\title{
The Prevalence of Intestinal Helminths Infections among Primary School Children in Calabar South Local Government Area, Cross Rivers State, Nigeria
}

\author{
Constancy Aleru', Sam Abbey ${ }^{2}$, Uchechukwu Obisike ${ }^{3}$, Ibioku Elekima ${ }^{4}$, Serekara Christian ${ }^{5}$, \\ Miriam Henshaw ${ }^{6}$
}

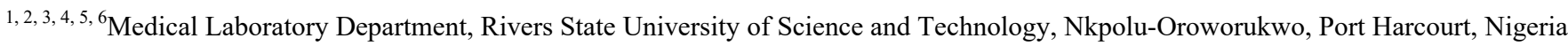

\begin{abstract}
The prevalence of intestinal helminths infections among primary school children in Calabar South Local Government Area, Cross Rivers State, Nigeria, was investigated. Out of 100 stool samples analysed from 5 primary schools in the area, 88 (88\%) were positive for different helminthiases. The number of pupils examined in each school was 20. Among the 5 primary schools examined in the area, Bishop King Memorial Primary School, Inyang Street (BKMS); Government Primary School, Mayne Avenue (GPSMA); The Apostolic Church Primary School, Idang Street (ACPS); Saint Mary's Primary School Annex, Anantigha (SMPSA) had the infection rate of $100 \%$ each, while Government Primary School, Hawkins Road (GPSHR) had the least infection rate of $40 \%$. The various helminths discovered were Ascarislumbricoides, Necatoramericanus(Hookworm), Strongyloidesstercoralis, Schistosomamansoni and Taenia species. In terms of the prevalence rate among the helminths, A. lumbricoides was the highest in number by 245 (49 \%), while Schistosomamansoni (3\%) was the lowest in number (15). As regards sex related infection rates, the males recorded the highest by 65 $\%$, while the females had $42.5 \%$. Children who were between the ages of 8 and 9 had the highest prevalence rate of 13 (76.5\%) when compared with children in other age groups. The sources of water supply used by the children in the area were also put into consideration; commercial borehole users, pipe- borne, stream and well had the infection rates of $34 \%$, $25 \%$, $23 \%$ and $6 \%$, respectively. In addition, in terms of the types of toilet facilities used by the children, pit latrine users were found to have the highest infection rate of $44 \%$, while the lowest (5\%) infection rate was found among bush/backyard users. Finally, various factors such as poor sanitation, poverty, ignorance and contaminated water sources were observed to enhance the prevalence of helminths infections in primary school children in the area.
\end{abstract}

Keywords: Helminthes; Infections; Prevalence rate; Intestinal

\section{Introduction}

In recent years, the prevalence of intestinal helminths infections has been well studied in the various African countries. These studies focused mainly on the prevalence of intestinal helminths infections among primary school pupils and gradually extended into the socio-economic factors of these infections among the children (Ekpenyong and Eyo, 2005; Muniz, 2008; Oblukwuet al., 2008; Ezeagwunaet al., 2009). According to studies, helminths infections are widespread in Africa with high prevalence rate in Nigeria, Ivory Coast, Angola, New Guinea, Rhodesia and Kenya (Muniz, 2008). In 2008, Anosike and his colleagues recorded that in a world of 2,200 billion inhabitants, there existed over 2,000 million helminths infections with about 1.5 million Nigerians suffering from Ascariasis alone, while there are several thousand with Strongyloidiasis, Trichuriasis, Enterobiasis and Hookworm infections. The high prevalence rate of intestinal helminths in Nigeria, especially among primary school children was confirmed by Dada-Adegbola and his colleagues who recorded $68.2 \%$ prevalence rate of intestinal helminths from stool samples of Children aged 0-7 years (Dada-Adegbolaet al., 2005).

The prevalence of helminths infections is of major public health concerns. This is because the factors that predispose man to the infections are bound in the sub-regions; the factors include: unhygienic environment, poor personal hygiene, poverty, malnutrition and ignorance (Ijagbone and Olagunju, 2006). Children between the ages of 4 and 16 have been reported by different researchers to have the highest prevalence rate. They are the most vulnerable age group among school children (Ekpenyong and Eyo, 2005; Oblukwuet al., 2008; Ezeagwunaet al., 2009). Among primary school children were reported heavy worm infections and the researchers stated that it is because they were vulnerable to malnutrition deficiency (Bethonyet al., 2006). Also, the use of bushes, streams and pit latrines for defecation has been reported to increase the prevalence rate of helminths infections in pupils than the use of water cistern. As a result of poor hygiene, it has been found that the Nigerian currency notes, which the primary school children handle and lick, harbour the ova of helminths (Dyke, 2001; Ekejinduet al., 2005). Researches have also been carried out that compared the infection rates between the males and females school children. It was reported that the females had the highest prevalence rate compared to the males (Oblukwuet al., 2008; Ezeagwunaet al., 2009). In addition, high prevalence rate was recorded among those whose parents were farmers and traders than those whose parents were civil servants. They opined that the reason is because the children, mostly the female children assisted their parents in farm works and other home chores (Oblukwuet al., 2008).

This study was carried out to determine the prevalence of intestinal helminths infections among primary school children in Calabar South Local Government Area, Cross Rivers State. The influence of age and gender of the children, their parents' occupation, the water sources and toilet facilities on the prevalence of intestinal helminths infection among the primary school children were also determined. According to this study, the prevalence of the 


\section{International Journal of Science and Research (IJSR) \\ ISSN (Online): 2319-7064}

Index Copernicus Value (2013): 6.14 | Impact Factor (2014): 5.611

infection exists among the children and, age and gender of the children their parents' occupation, water sources and toilet facilities the children used were found to influence the rate of helminths infection.

\section{Materials and Methods}

\subsection{Study Area}

Calabar South Local Government Area is in city of Cross Rivers State. It is situated at latitude $04^{\circ} 58$ ' $\mathrm{N}$ and longitude $08^{0} 25^{\circ} \mathrm{E}$ along the coastal plains of Nigeria. It is a rainforest belt located near the Atlantic Ocean with high annual rainfall of $144.09 \mathrm{~mm}$ (Menakaya and Floyd, 1965). Majority of the parents/guardians and inhabitants are mostly farmers, traders and civil servants. Most of the residential buildings in the area are general compounds with few bungalow and storey buildings. Greater number of the toilets are pit latrines with a few number of water cistern.

In the area, pipe-borne water is rare while the sources of drinking water are mainly commercial borehole water for domestic use. Few persons residing near the river bank use the stream as their own sources of water supply as they cannot afford buying water every day due to high rate of poverty. There are twenty-three primary schools in Calabar South, Local Government Area with pupils' population of 22500. The pupils are drawn from different sociological and economic backgrounds.

\subsection{Study Sites/Population}

The population of the study was 100 pupils and five out of the twenty-three primary schools were randomly selected for the study. The five primary schools were: Bishop King Memorial Primary School, Inyang Street (BKMS); Government Primary School, Mayne Avenue (GPSMA); Government Primary School, Hawkins Road (GPSHR); The Apostolic Church Primary School, Idang Street (ACPS); Saint Mary's Primary School Annex, Anantigha (SMPSA). For the purposes of enlisting subjects into the study, one arm of each class in the schools was selected using the same table of random numbers method. Therefore, 20 pupils with age range between 5 and 16 years, comprising both genders were drawn in each school.

\subsection{Sample Collection}

Each pupil from the five primary schools was given a simple primary school based questionnaire and a wide-mouthed transparent container (universal bottle). The containers and questionnaires were given to 100 randomly selected pupils in the selected schools. The questionnaires were distributed to the pupils to determine the name, age, sex, occupation of their parents, their residence premises and source of drinking water, toilet facilities and how long they have been treated with anthelminthic drugs. The pupils were asked to take the containers home and instructions were given to them on how to fill the questionnaires and to return the samples the next day. The name, sex and age of each pupil were noted after the samples had been collected and labelled. Then, the samples were transported to the laboratory for analysis using the formal ether concentration technique and floatation concentration technique (Cheesbrough, 2000).

\subsection{Formal-ether concentration technique}

Using an applicator stick, $1 \mathrm{~g}$ of stool sample was homogenized and emulsified in $4 \mathrm{ml}$ of $10 \%$ formal saline contained in a tube. The emulsified faeces was strained into a centrifuge tube using a fine sieve of $1 \mathrm{~mm}^{2}$. Then, $4 \mathrm{ml}$ of diethyl ether was added to the filtrate. The tube was stoppered, the filtrate mixed for 1 minute and centrifuged at $1000 \mathrm{~g}$ for 1 minute. Thereafter, applicator stick was used to loosen the suspended faecal debris and the supernatant decanted. The bottom of the tube tapped to re-suspend and mix the sediment. Then, the sediment was transferred into a clean glass slide using a Pasteur pipette and a drop of lugol iodine solution added to colour the parasite for easy identification. The coverslip was placed on the slide and the slide examined microscopically, using $\mathrm{x} 10$ and $\mathrm{x} 40$ objectives for helminths' ova and larvae. Identifications of the parasites were done using the identification chart.

\subsection{Floatation Concentration Technique}

Another analytical method used was a floatation technique. In this method, $33 \%$ sulphate solution, which was prepared by dissolving $33 \mathrm{~g}$ of zinc sulphate crystals in $100 \mathrm{ml}$ of distilled water. Test tubes $(5 \mathrm{ml})$ were filled with zinc sulphate solution up to a quarter of the tubes. An estimated $0.5 \mathrm{~g}$ of faeces was added to each test tube and emulsified with a plastic stirring rod and was mixed properly. The tubes were kept in a vertical position in a test tube rack. A Pasteur pipette was used to add further solution of zinc sulphate to ensure the tubes were filled to the brim. A cover-slip was carefully placed on top of each filled tube; this was allowed to stand undisturbed for 35-45 minutes for the cysts and ova to float. Thereafter, the cover-slip was lifted and placed on the slide faced downwards. The ova and cysts of the intestinal helminths that adhered to the cover-slip were examined microscopically using x10 and x40 objectives. The number of the different parasitic helminths found was counted and recorded (Cheesbrough, 2000).

\section{Results}

\subsection{Distribution of intestinal helminths infections among primary schools in Calabar South Local Government Area (LGA), Cross Rivers State}

Out of 100 stool samples examined from 5 primary schools in Calabar South LGA, 88 pupils were positive for various intestinal helminth parasites. Of the 100 pupils, 20 were examined from each primary school and the results are distributed as follows: Bishop King Memorial Primary School, Inyang Street 20 (100\%), Government Primary School, Mayne Avenue 20 (100\%), Government Primary School, Hawkins Road 8 (40\%), The Apostolic Church Primary School, Idang Street 20 (100\%) and Saint Mary's Primary School, Annex Anantigha 20 (100\%). Figure 1 shows the distribution according to schools. 


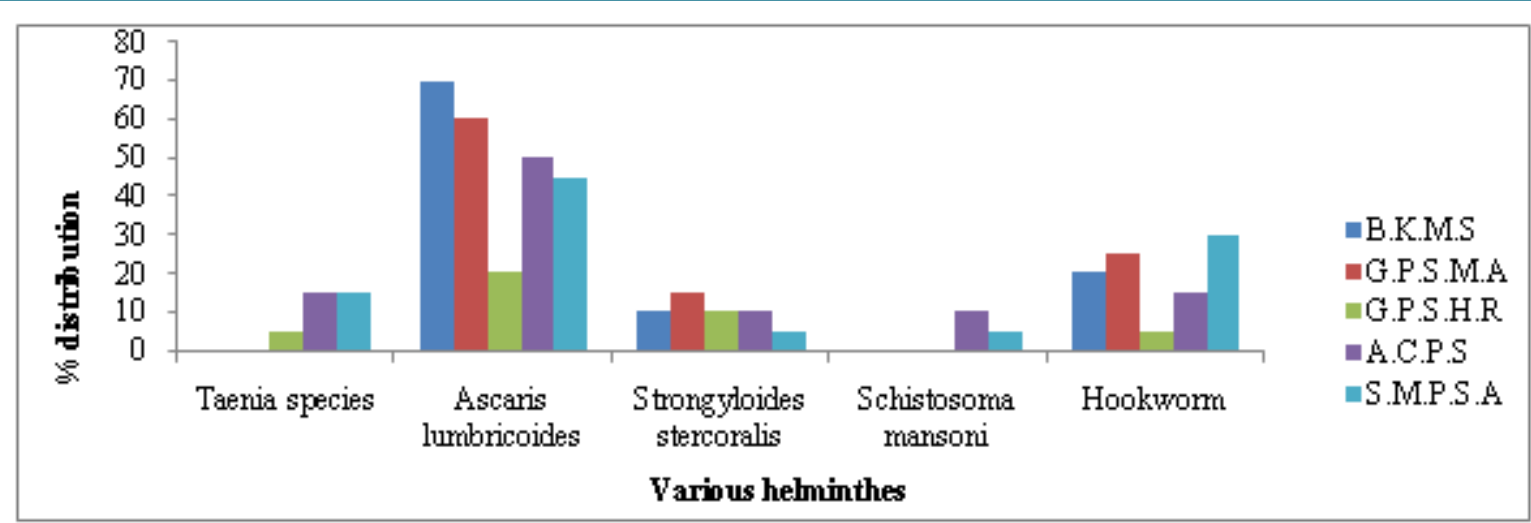

Figure 1: Distribution of intestinal helminths infections with respect to schools

3.2 Prevalence of intestinal helminths infections among primary school children by their age and gender

As illustrated in figure 2, the prevalence rate of helminths infections was higher among 8-10 age group by 13 (76.5\%) with the males having the highest rate of $10(83.3 \%)$ However, the age group 14-16 had the lowest prevalence rate of $9(47.4 \%)$.

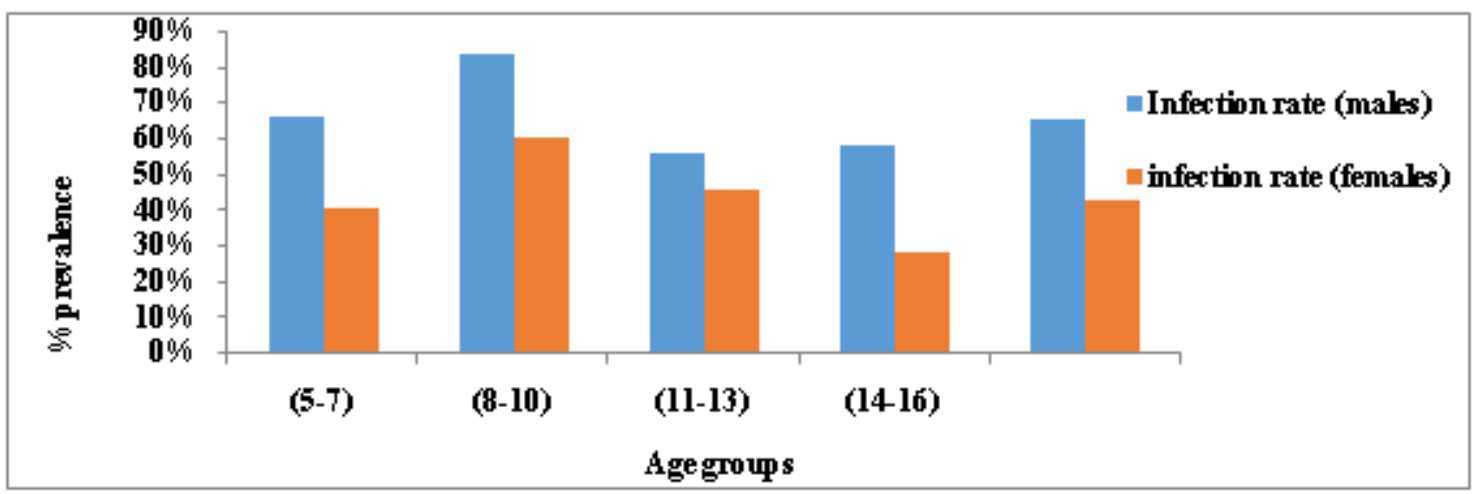

Figure 2: Prevalence of intestinal helminths infections with respect to age and gender

rate. The result also shows that age group 5-7 had the highest percentage rate of infection caused by species of 3.3. Percentage distribution of various ova of intestinal helminths among the different age groups

Hookworm. In addition, the illustration in figure 3 shows that Taeniasis and Schistisomiasis are not prevalent in the

According to figure 3 , all the age groups had intestinal helminths infections and the highest percentage rate of area when compared to other intestinal helminths infections.

Ascarislumbricoides was recorded among age group 8-9

(34.4\%), while age group 14-16 had the lowest percentage

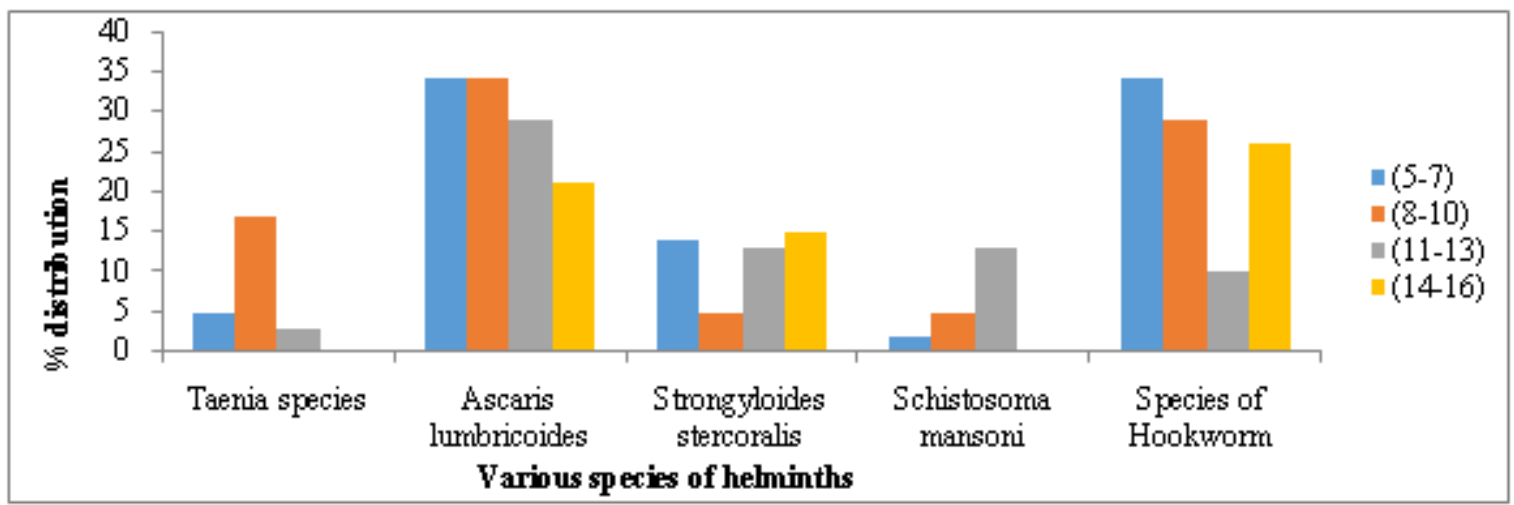

Figure 3: The percentage distribution of various ova of intestinal helminths by the age groups

3.4. Percentages of mixed infections among primary school children in the area

As shown in figure 4, the percentage distribution of mixed infections among school children in Calabar South LGA is as follows: Ascarislumbricoides and the species of Hookworm 23 (41.1 \%); Ascarislumbricoides, Hookworm and Trichuris species 12 (7.2\%); Ascarislumbricoidesand Strongyloidesstercoralis 4 (7.1\%); Ascarislumbricoides and Schistosomamansoni2 (3.5\%); Ascarislumbricoides and the 


\section{International Journal of Science and Research (IJSR) \\ ISSN (Online): 2319-7064 \\ Index Copernicus Value (2013): 6.14 | Impact Factor (2014): 5.611}

species of Hookworm and Taenia species I (1.8\%). The highest percentage rate was the mixed infection of Ascarislumbricoides and the species of Hookworm, while the least percentage rate was of Ascarislumbricoides, and the species of Hookworm and Taenia species I (1.8\%).

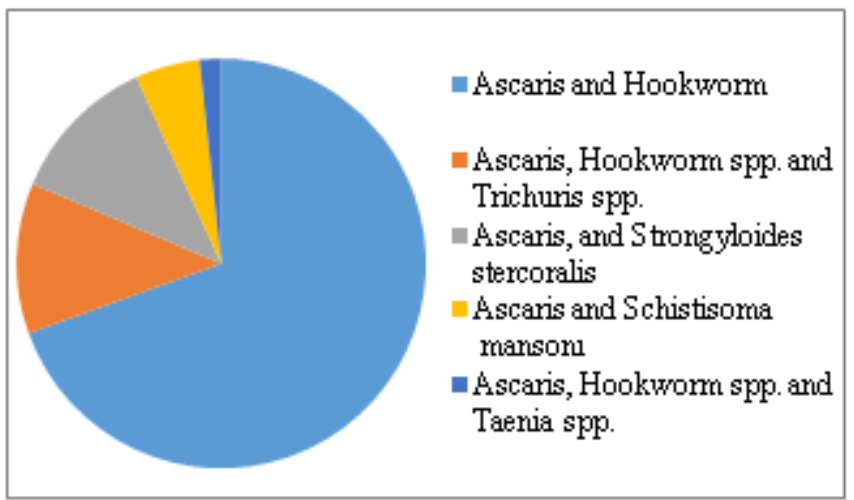

Figure 4: Percentages of mixed infections among primary school children in the five primary school inthe area
3.5. Prevalence of intestinal helminths infections among primary school children based on sources of toilet facilities

A total of 44 pupils representing $50 \%$ of the total number of respondents used pit latrines, $26(29.5 \%)$ used water cistern, $13(14.7 \%)$ used river bank and $5(5.7 \%)$ used the bush/backyard. According to findings, the highest prevalence rate was recorded among pupils who used pit latrine (44\%), while the least was among those who used bushes/backyards (figure 5). The prevalence of $A$. lumbricoides (49 \%) was significantly higher than other parasitic helminths, while Taenia spp. (7\%) were the lowest, followed by Schistosomamansoni (8\%).

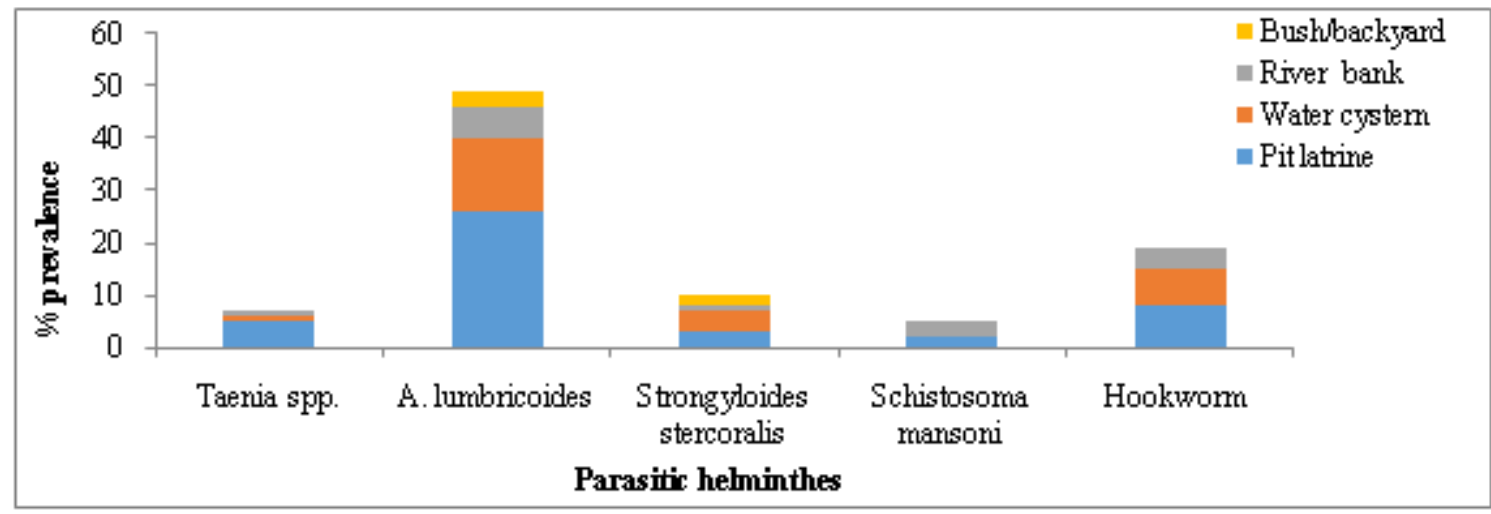

Figure 5: Prevalence based on sources of toilet

3.6 Percentage distribution of intestinal helminths infections among primary school children based on sources of water supply

By way of illustration, figure 6 shows that the prevalence of parasitic helminths among well users $(6 \%)$ was significantly lower than the others. Commercial borehole users $(34 \%)$ had the highest prevalence rate of parasitic helminths infections, followed by pipe-borne (25\%) and stream (23 $\%)$. A. lumbricoides (40\%) was the most predominant, followed by Strongyloidesstercoralis (10 \%), Schistosomamansoni (10\%) and Taenia spp. (7\%).

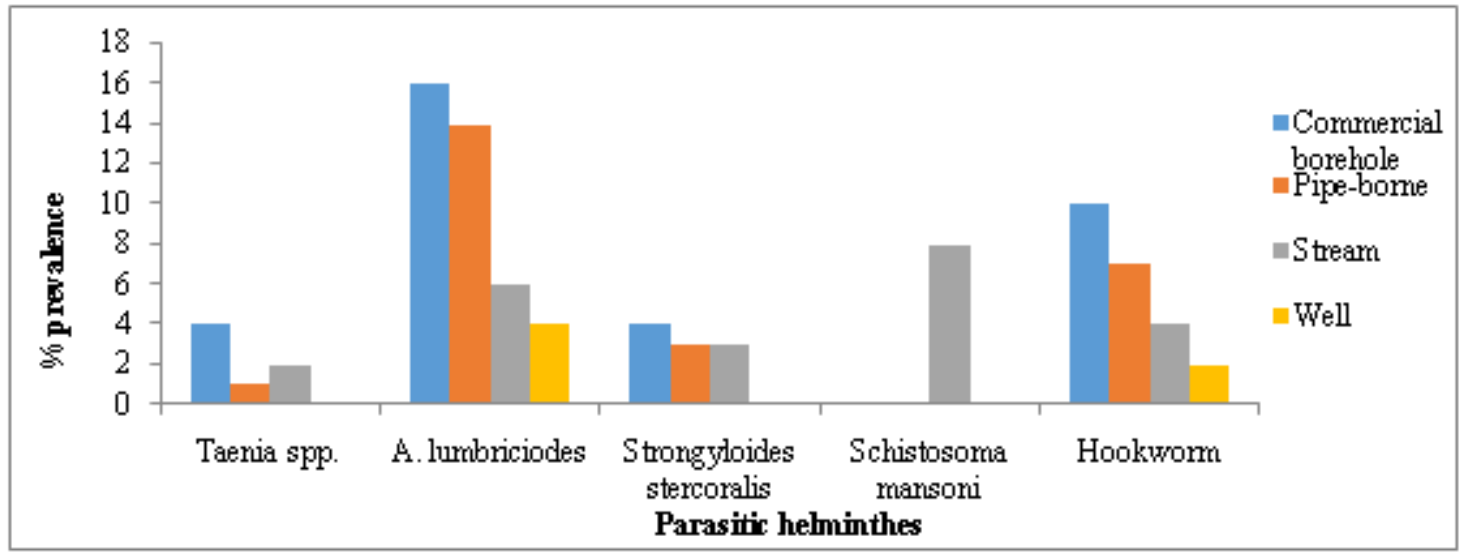

Figure 6: Prevalence of parasitic helminths based sources of water supply 


\section{International Journal of Science and Research (IJSR) ISSN (Online): 2319-7064}

Index Copernicus Value (2013): 6.14 | Impact Factor (2014): 5.611

\section{Discussion}

The results of this investigation revealed that $88(88 \%)$ out of 100 children from the five primary schools in Calabar South Local Government Area, Cross Rivers State were infected with helminthiases. This may show the general trend of the problem among school children throughout Cross Rivers State and in the country, as environmental condition is the same in Nigeria. Also, factors such as unhygienic environment, poor personal hygiene, malnutrition, ignorance and poverty, which predispose man to the infections, are bound in Nigeria. The prevalence of intestinal helminths infections was so high that four out of the five primary schools used for the study had $100 \%$ infection rate. This high prevalence rate recorded is similar to observations from other parts of Nigeria (DadaAdegbolaet al., 2005; Anosikeet al., 2008; Muniz, 2008).

Generally, five types of helminths were found: Strongyloidesstercoralis, species of Hookworm,Taenia species, Schistosomamansoni and Ascarislumbricoides. There were variations observed in the prevalence of each species of helminths. For example, the prevalence of $A$. lumbricoides was significantly higher than other intestinal helminths encountered. However, the prevalence of Schistosomamansoni was the lowest (4\%), followed by Taenia species (6\%), Strongyloidesstercoralis (13\%) and Hookworm species $(25 \%)$. The relatively high prevalence of Ascarislumbricoides here agrees to previous findings (Ezeagwunaet al., 2009). A similar observation was made by Adeyeba and Akinlahil when they conducted a study on intestinal parasitic infections among school children in rural community of Igbora in Oyo State, Nigeria. They recorded that out of 554 school children examined, 279 (50.4\%) were infected with intestinal parasites. The unhygienic habit of going to school and farm barefooted may be connected to the increase rate of parasitic intestinal helminths infections in the area.

Similarly, the prevalence of these parasitic helminths varied significantly among the age groups with age group 8-10 (76.5\%) highly infected, followed by $5-7$ (54.3\%), 11-13 $(51.7 \%)$ and the lowest was $14-16(47.4 \%)$. The prevalence also varied significantly with sexes, with males (65\%) having comparatively more percentage of parasitic helminths than the females $(42.5 \%)$. The findings that age group 8-10 has the highest prevalence rate is similar to the findings by Oblukwu and his colleagues (Oblukwuet al., 2008). This observation could be attributed to more exposure of this age group to sources of infection through school activities and environmental pollution than the other age groups as well as the state of their immunity. Children between 8 and 10 years old fall into the group that engages in outdoor activities; at this age, they are generally reservoirs of parasitic helminths and are important in perpetuating the transmission. Also, this age group assists their parents in the farm and they eat foods and snacks wrapped with ordinary papers from none reliable sources. Without assistance, they may not wash their hands properly before eating and after working in the farm or playing in the school.

The results that the prevalence of intestinal helminths is more in males than in females are surprising because they are different from the results of previous studies. For instance, the report from Ezeagwuna and his colleagues as well as Oblukwu and his co-researchers showed that the female primary school pupils had the highest prevalence rate compared to the males (Oblukwuet al., 2008; Ezeagwunaet al., 2009). The difference in the results from this study and findings from the works of other researchers could be due to the development of the areas of study and the activities of both genders in these areas. In Calabar South LGA, of Cross Rivers State, the male pupils were seen assisting their parents more with domestic activities than the females. The males also engaged in more daring adventures such as footballing, hunting, fishing and swimming in the streams than the females.

According to the results of this study, the lack of good toilet facilities is a significant prediction for the spread of helminths infections in the area. Among 88 pupils who were positive with helminthiases, $44(50 \%)$ of them used pit latrines, $26(29.5 \%)$ used water cistern, 13 (14.7\%) used river bank and $5(5.7 \%)$ used the bush/backyard. The highest prevalence rate was recorded among pupils who used pit latrines (44\%), while the least was among those who used bushes/backyards. The high infection rate observed among the children who used pit latrines may be attributed to the fact that microbial contaminants as well as discharges of chemicals from the pit latrines enter the groundwater and these microbial contaminants may include different species of helminths. Also, it was observed that the most common type of human excreta disposal system in the area is the pit latrines; their use is really on the rise in the LGA.

This study shows that water is one of the factors that contributes to the high prevalence of intestinal helminths infections in Calabar South LGA. Most of the residents of this area depend on commercial borehole and stream; they prefer these two sources to the other sources of water supply as some poor families cannot afford the cost of buying treated water from reliable sources. Unfortunately for them, the boreholes are dug very close to the pit latrines and the water from the boreholes is consumed by the same people; this is confirmed from the results of this study. For instance, the commercial borehole users had the highest prevalence rate of the infection (34\%) than those who used other sources of water sources. When those who are infected defecate, ova of the helminths enter the groundwater where they (mostly A. lumbricoides) stay alive and as people in the area fetch and consume the water, they become infected. The findings showed that $A$. lumbricoides was the most prevalent $(40 \%)$ and this is because the ova have a lipid layer that makes them resist to the effects of acid and alkalis, as well as other chemicals. This resilience helps to explain why A. lumbricoides is such a ubiquitous parasite. Also, according to observations from this study, the use of pipe borne and streams is as bad as the use of commercial boreholes even if the percentages may vary.

At times, people in the area go to the stream to pass excreta (faeces) and it is the same stream they fetch water to drink and the pupils go to bath. The use of well seems better from the findings got and this may be because most wells in the area are not dug too deep to be connected to the groundwater

\section{Volume 5 Issue 2, February 2016}




\section{International Journal of Science and Research (IJSR) \\ ISSN (Online): 2319-7064}

Index Copernicus Value (2013): 6.14 | Impact Factor (2014): 5.611

and wells have seasons they dry up. As they dry up, the ova of helminths including the ova of A. lumbricoides may be destroyed as the dry season could last longer at times. Among the population, mostly the poor, pit latrines and streams are seen as beneficial because they are believed to prevent offensive odours, provide privacy and prevent environment free of faeces. However, these means are not the best as there is no standard of pit latrine and a limit to which the people should dig the pits in order to avoid faeces going into the groundwater.

Overpopulation in the area is observed as one of the factors that contributed to the high prevalence rate of the infection; mostly among the pit latrines and commercial borehole users. This is because the pit latrines are dug very close to the boreholes vice versa. More so, poverty is another factor that contributes to the high prevalence rate of helminths infections in the area because the pupils followed their parents to the farm barefooted and also went to school without sandals. Observations from this study confirmed this as pupils whose parents are farmers and traders had more infections than those whose parents are civil servants.

\section{Conclusion}

The high prevalence of intestinal helminths infection may be used as an indicator of poor sanitary environment. The government of Calabar South LGA and that of the state should use worm survey in schools, which can be completed very easily and at low cost to monitor periodically the improvement taking place in the living conditions of the area surveyed. Improved dwelling premises with better human excreta disposal systems, good domestic water, general sanitation of the area and improved socio-economic status of the parents will help reduce infections in the area.

More so, massive education campaign to enlighten parents and children on helminthiases, how they are contracted and their control should be carried out by the government and nongovernmental organizations in schools through radio, television and newspaper. However, academic and health sectors should play a more leading role in creating awareness to the pupils, students and to their parents about environmental pollution in Calabar South LGA and Cross Rivers State.

\section{References}

[1] Ekpenyong, E.A. \&Eyo, E.J. (2005). Prevalence of intestinal helminthes infections among school children in tropical semi urban communities. Animal Research International, 5, 804-810.

[2] Muniz, P.T. (2008). The major human helminthiasis and their prevalence in Africa. Africa Journal of Clinical Investigation, 118, 1311-1321.

[3] Oblukwu, M.O., Umeunaeto, P.U., Eneaya, C.I. and Nwaorgu, G.O., (2008). Journal of Parasitology. 29, 15-19.

[4] Ezeagwuna, D.A., Anaghalu, I.C. \&Nwosu, D.C. (2009). The prevalence and socio-economic factors of intestinal helminthes infections among primary school pupils in Ozubulu, Anambra State, Nigeria. Internet Journal of Epidermiology, 4, 211-215.
[5] Dada-Adegbola, H.O., Oluwatoba, A.O. and Falade, C.O. (2005). Prevalence of multiple intestinal helminthes among children in a rural community. African Journal of Medical Science, 34, 263-367.

[6] Ijagbone, I.F. and Olagunju, T.F.(2006). Intestinal helminthe parasites among school children in Iragbiji, Boripe Local Government Area, Osun State, Nigeria. African Journal of Biomedical Research, 9, 63-66.

[7] Bethony, J., Brookers, S., Albonico, M., Geiger, S.M., Loukas, A., Diemert, D. and Hotez, P.J. (2006). Soil transmitted helminthes infections. Lancet, 367, 15211532

[8] Dyek, N.D. (2001). Prevalence of eggs and cysts of parents under the fingernails of primary school pupils in Samaru, Zaria, Nigeria. MSc. Thesis, Ahmadu Bello University Zaria.

[9] Ekejindu, I.M., Ekechukwu, A.C. and Ezeagwuna, D.A. (2005). Prevalence of parasitic oocysts and ova on Nigerian currency (Naira). Journal of Biomedical Investigation, 3, 16-20.

[10] Menakaya, J.C.andFloyd, B.N. (1965). Macmillan junior atlas for Nigerian. London: Macmillan Press

[11] Cheesbrough, M., (2000). District laboratory practice in tropical countries, part 2. Cambridge: Cambridge University.p,464-465.

[12] Anosike, J.C., Zacchaeus, V.O., Abanobi, O.C., Dada, E.O., Oku, E.E., Keke, I.R. and Uwaezuoke, J.C. (2005). Studies on the intestinal worm (Helminthiasis0 infestation in a central Nigerian rural community. A world bank assisted National Agricutural Research Project (N.A.R.P) - University of Port Harcourt. Journal of Applied Science Environmental Management, 10, 61-66. 